\title{
Grupo de convivência na Estratégia Saúde da Família como espaço de ações colaborativas e trabalho interprofissional em saúde - relato de experiência de uma disciplina interprofissional na graduação em saúde
}

Grace Jacqueline Aquiles, Ana Paula Neri, Luciana da Conceição dos Santos, Mara Rubia Violin da Silva, Marcia Adriana Zavatini

\section{Resumo}

Esse trabalho relata a experiência vivenciada por um docente de um curso de graduação em saúde e um grupo de dez estudantes dos cursos de Biomedicina, Enfermagem, Farmácia, Medicina, Psicologia e Odontologia de uma universidade pública da região noroeste do estado do Paraná, trabalhadores de uma Unidade Básica de Saúde (UBS) e usuários na realização das atividades curriculares da disciplina denominada Atenção em Saúde. Essa disciplina tem caráter interprofissional, interdisciplinar e inteiramente conformada com base nas metodologias ativas de ensino. O desenvolvimento da disciplina dá-se no território de uma Unidade Básica de Saúde de uma cidade de médio porte do noroeste paranaense, na primeira série dos sete cursos envolvidos (no grupo desse relato não havia estudantes do curso de Educação Física), tem a adoção da integralidade em saúde como eixo orientador da formação objetivando a mudança dos processos de trabalho e propõe a construção de um perfil acadêmico e profissional de competências e habilidades para atuação com qualidade e resolutividade, tendo como referencial os princípios do Sistema Único de Saúde (SUS) e o reconhecimento do papel central do estudante no processo ensinoaprendizagem como sujeito ativo de sua própria construção. Embora o SUS e as Diretrizes Curriculares Nacionais (DCN) enfoquem o trabalho em equipe, o modelo predominante de educação em saúde no Brasil é unidisciplinar (Feuerwerker, 2013) caracterizado principalmente pelo foco em disciplinas que acabam por sedimentar a fragmentação do cuidado, dos saberes e das práticas, o corporativismo profissional e, por fim reforça o tradicional modelo biomédico, "procedimento centrado" e com super valorização dos saberes técnicos isolados por profissão e dos territórios institucionalizados. Assim, a disciplina de Atenção em Saúde supõe o fortalecimento do modelo de atenção "usuário-centrado", com valorização dos processos relacionais ocorridos no encontro entre a academia, com seus professores e estudantes, o trabalhador de saúde e o usuário no seu território. O que buscamos com a construção cotidiana dessa disciplina é destacar a potencialidade que ela apresenta enquanto oportunidade de vivências diversas, nos encontros interprofissionais que ela provoca, nas intervenções que ela propõe e no recurso que ela representa para pensar novas formas de realizar o trabalho em saúde, de se inserir na dinâmica das equipes já constituídas nas instituições de saúde e de manifestar a colaboração ativa nas equipes da Estratégia Saúde da Família, onde ela formalmente se aloca no curso do seu desenvolvimento na UBS. Nesse relato, especificamente, objetivamos descrever como os acadêmicos dos seis cursos de Atenção em Saúde, realizaram suas atividades curriculares em um grupo de convivência, no território da UBS onde vivenciaram a disciplina, no ano de 2017. O objetivo das atividades desenvolvidas pelos acadêmicos no grupo foram compreender a atenção em saúde usuário centrada; experienciar a colaboração ativa e o trabalho interprofissional; reconhecer a existência de espaços transformadores no processo saúde-doença; entender o grupo de convivência como uma ferramenta na atenção em saúde para o empoderamento dos sujeitos, frente à dura realidade a ser enfrentada cotidianamente em todas as suas interfaces e desenvolver habilidades relacionais tomadas como recursos essenciais da proposta de transformação de desenhos assistenciais, compreendidas na Estratégia Saúde da 
ISSN 2179-6750

Família (CIAMPONE et aI, 2000). Metodologia: Na UBS em que foram desenvolvidas as atividades aqui relatadas há um grupo de convivência formado por mulheres adultas, em sua maioria acima de 60 anos, moradoras de uma mesma microárea no território da unidade. Esse grupo reúne-se mensalmente, na quinta-feira à tarde sob a coordenação de uma Agente Comunitária de Saúde e da Enfermeira da Equipe da ESF. As semelhanças do grupo resumem-se ao gênero e a faixa etária. Nesse encontro há uma riqueza de diversidade com relação às histórias de vida, modos de viver, conjugalidade, arranjos familiares e compreensão do processo saúde-doença. Há portadores de condições crônicas de saúde como distrofia muscular (cadeirante), deficiente visual total, transtornos mentais e outros, no entanto as patologias não são abordadas diretamente no grupo e não fazem parte dos diálogos e intervenções que ocorrem ali. Inicialmente o pretexto dos encontros era a troca de livros para leitura durante o mês, advindos de doações diversas e emprestados às interessadas, que os comentavam com o grupo, no encontro seguinte como forma de valorização da atividade. Com o tempo o grupo constituiu uma dinâmica própria, de encontros mais afetivos, dando espaço para uma palavra profissional, conversas informais, trocas de experiências e partilha de um café da tarde. Os encontros acontecem sempre na casa ofertada por uma participante do grupo. Nos meses em que houve a oportunidade da participação do grupo da universidade (acadêmicos e professora) a programação ficou por conta desses. Foram programados três encontros e o tema central foi a "autoestima". No primeiro encontro a referência foi "Minha História" e foram realizadas dinâmicas onde as participantes puderam retratar suas histórias de vida, com perdas e conquistas e valorizadas as falas de cada uma, com acolhimento de suas emoções manifestas. Também foram realizadas fotografias individuais de cada mulher a serem devolvidas em porta retratos no último encontro. Ao final, as mulheres escolheram músicas e cantaram juntas enquanto os estudantes tocavam instrumentos. No segundo encontro a referência foi "Espelho Meu" e cada participante pode se olhar no espelho e falar de suas virtudes. O terceiro encontro está previsto para dezembro, como o tema "Eu sou um presente" quando receberão as fotografias e também compartilharão lembranças entre si. Para cada encontro os estudantes e professor, juntamente com os trabalhadores da UBS estabeleciam uma agenda de atividades, dividiam as tarefas e procediam à organização do encontro desenvolvendo competências relacionadas ao trabalho e compreendendo que o conteúdo que cerca determinada ação é apenas o elo que une os saberes, mas que cada um é muito mais potente quando está trabalhando na resolução de necessidades cotidianas com uma liderança colaborativa e quando se compreende a dinâmica de funcionamento da equipe. Resultados: A vivência da disciplina Atenção em Saúde por docente, estudantes e trabalhadores em saúde é um caminho para fortalecer as mudanças desejadas nos modelos de atenção, com ênfase no trabalho em equipe colaborativo, interprofissional e usuário centrado. Integrar diferentes áreas do saber pressupõe a interação dos profissionais que contribuem para o cuidado numa compreensão ampliada de grupo e de espaços de intervenção. Conclusão: Muitos são os desafios na educação para o SUS, mas múltiplas são igualmente as possibilidades que existem nas atividades de integração ensino-trabalho-cidadania com a colaboração interprofissional. Profissionais de saúde, docentes e estudantes devem estar inseridos na prática da atenção em saúde, principalmente nos encontros dos estudantes das diversas profissões da saúde com os usuários do SUS, onde se pode vivenciar a produção de um cuidado integral, que considere a complexidade da vida, a variedade dos espaços terapêuticos, a compreensão diversa do processo saúde- doença e da atenção aos sujeitos e às coletividades.

Descritores: Graduação em saúde, Trabalho interprofissional, Atenção básica, Estratégia saúde da família 